\title{
The Implementation of Inquiry-teaching Mode in Electronic Experiment Course
}

\author{
Li Hong, Li Kai ${ }^{{ }^{*}}$,Li Ying, Wang Xianlei \\ Ordnance NCO Academy Army Engineering University, Wuhan, Hu Bei, China \\ a442787707@qq.com \\ ${ }^{*}$ Corresponding author
}

Keywords: Inquiry; Experiment; Teaching.

\begin{abstract}
In order to cultivate students' independent spirit, experiment teaching should not stay at the verification stage from the known knowledge to the known conclusion, but rise to the inquiry experiment. Inquiry experiment teaching mode has changed the teaching method of verification in experiment. In the process of inquiry teaching, students can experience the cognitive process of discovering problems, independent thinking, active exploration, theory guiding practice and practice testing theory. They can develop intelligence imperceptibly and convert knowledge into ability.
\end{abstract}

\section{Introduction}

At present, the teaching mode of electronic technology experiment basically follows the mothod of "teacher teaching circuit theory knowledge in the classroom - teacher demonstrating the experiment process in the laboratory -- student imitating to do verification experiments"[1]. In this "imitation" teaching mode, most of the experiments done by students are confirmatory and formative. While experimental teaching for the cultivation of comprehensive application ability is less arranged, which is not enough to improve students' ability and cultivate students' innovation consciousness. Experimental teaching should not only help students to deepen the understanding of circuit theory and circuit knowledge, but also to train students' exploration ability. Therefore, it is necessary to deepen the reform of experiment teaching and strengthen inquiry experiment teaching mode.

\section{The characteristics and purpose of inquiry experiment teaching mode}

In the process of electronic experimental teaching, there are factors for learning and digesting knowledge, as well as factors for discovering problems and generating questions. Therefore, experiment teaching should not just stay at the stage of verifying theoretical knowledge, but rise to inquiry experiment. Inquiry experiment teaching mode refers to the students, following the guidance of teachers, can study teaching contents by independent learning, actively exploring, exchanging and cooperation $^{[2]}$. It is a mode combine study and explore and its prominent feature is to pay attention to the students thinking ability, innovation ability and cooperation ability. Inquiry experiment is not a process that students passively accept knowledge, but a process of active thinking, cooperative discussion and hands-on operation to discover new knowledge and solve problems with the knowledge and skills they have learned. The problems of inquiry can be derived from the key points and difficulties in teaching or the puzzling phenomena in experiments. In inquiry experiment teaching mode, students have no ready-made answers to the problems in the textbooks. They need to search for information, discuss, analyze problems and draw up practical steps and solutions.

It can be seen that inquiry teaching is mode that apply the method of scientific research to teaching. Students through the exploration of problems to discover new knowledge, deepen the depth of learning and broaden the breadth of learning. The guiding ideology of inquiry teaching is the heuristic teaching concept of "student-centered and teacher-led". Teachers upgrade teaching mode from the level of knowledge imparting and skill training to the level of guidance of scientific methods and cultivation of scientific thinking. 


\section{The implementation of inquiry experiment in electronic technology}

\subsection{Set goals of ability}

On the basis of mastering the basic skills of verification experiment, the goals of ability that inquiry experiment requires are as follows. First, students can arrange the experiment content and procedures reasonably and independently according to the research issues and topics. Second, students have the ability to choose the necessary equipment and instrumentation of the experiment and can use these devices correctly and safely. Third, students have the ability to master to measure the required data and observe the results correctly.Fourth, experiment data and results can be analyzed and derived correctly.Fifth, students form the ability to analyze and apply the knowledge comprehensively, and have the ability to analyze and indentify common circuit faults by themselves.

\subsection{Set inquiry questions}

Inquiry-based teaching encourages students to propose and discover questions actively and boldly. Inquiry-based teaching combines theoretical knowledge learning and knowledge exploring, which is a breakthrough in teaching concept.

After completing the verification experiment, students should set questions to inquire on the basis of mastering the basic skills of electronic experiment. Teachers should encourage and guide students to cultivate awareness of discovery and tell them that it's important to come up with new ideas themselves in learning period. This means not only learning new knowledge, but also having new discoveries and new experiences. There are four principles should be followed during the subject setting of inquiry experiments. First, the key contents of teaching should be reflected. Second, knowledge should be new for students. Third, knowledge should be adapt to the students' existing knowledge level, cognitive level and research ability. Fourth, the inquiry questions usually put forward by teachers carefully, or by students when they come across questions in the experiment. For example:

Inquiry question 1: In the bridge rectifier circuit experiment, $9 \mathrm{v} \mathrm{AC}$ voltage from the signal generator connect to the input end of the rectifier circuit, the full-wave rectifier output voltage, also called the pulsating dc voltage can be observed on the output side. But the angle of waveform that some classmates observed on the output side is less than 180 degrees, Why does this happen?

\section{Literature references}

Inquiry question 2: The basic experiment of single-tube common-emitter amplifier circuit is to connect the circuit, test the static working point, test the amplification factor and input resistance and output resistance, etc. On this basis, teachers can inspire students to think, what are the factors that affect the static work point? If the static operating point changes and deviates from the appropriate value, will it affect the performance of the amplifier circuit? What kind of impact will be? How to deal with these effects?

Inquiry question 3: the voltage amplification factor of the common collector amplifier circuit is equal to 1. What are the characteristics of its input resistance and output resistance? How to apply these characteristics? How to apply it to work in conjunction with a common emitter amplifier circuit?

\subsection{Lead exploration and verification}

Students have the spire for knowledge when they face problems. In the process of thinking about the reasons and searching for the answers, most of the students have the feeling that a book is known in time of need. At this time, teachers should make the best use of the situation and guide students to learn scientific research methods and check references themselves. It is a process that students seach the information and study hard to find answers with teacher's guidence so that they can finally definite the plan of problem solving and retest it.

In the experiment of single-tube common-emitter amplifier circuit, students found that the resistance value of base resistance, collector resistance and power supply voltage value of the amplifier circuit would affect the working point of the circuit. If the working point is too high, 
saturation distortion would occur; if the working point is too low, cut-off distortion would occur ${ }^{[3]}$. So how to eliminate the distortion? What is the best solution?With the guidance of teachers, students found that if changing the power supply voltage can affect the other circuit with common power supply, changing the collector resistor value will affect the communication load of amplifying circuit, thus influence on the performance of the circuit amplification. So changing the base resistance can effectively adjust the static working point and performance indicators and little influence on communication. Through hard work, students find the best way to solve problems and experience the joy of learning.

In the emitter output circuit experiment, students know that its magnification is only 1 and can't amplify the input signal voltage, the input resistance is big and output resistance is small. With these characteristics, it can be used as input pole, intermediate buffer, output pole in multi-stage voltage amplifier, do the good assistant of the common emitter amplifier circuit, to make the AC signal transmission with greatly increased efficiency.

The structure of the differential amplifier is designed to suppress zero drift or temperature drift. The characteristic of its circuit structure is that it is symmetrical in structure, and the more consistent the component parameters are in the corresponding position of the differential amplifier, the better the effect of eliminating zero drift will be ${ }^{[4]}$. When doing this experiment, some students found that the amplification factor of the double-end output was only more than one time of the single-end output, which was inconsistent with the theoretical knowledge. The reason was that the amplification coefficient of the two transistors was inconsistent. The students used a multimeter to measure the current amplification factor of the two transistors, and found that the amplification coefficients of the two transistors were indeed inconsistent. Then they replaced the two tubes with basically the same parameters, and tested the output signal voltage to obtain satisfactory results. Through analysis, judgment and practice, students can have a deeper understanding of theoretical knowledge, improve their ability and enhance their interest and confidence in learning.

Inquiry experiment changes the teaching method of verification experiment. In order to reduce the psychological dependence of students and cultivate their spirit of independence, teachers should give them opportunities to operate experimental instruments and choose proper experimental methods as well as the arrangement of the experimental steps. While this does not mean that students are unattended.In fact, teachers must pay attention to patrol and tutor students to operate experiment standardly so as to eliminate potential safety problems and ensure the safety of the experiment.

In the process of inquiry teaching, Students experience the cognitive process of discovering problems, thinking independently, exploring actively, guiding practice with theory and testing theory with practice. They develop intelligence and turn knowledge into competence gradually.

\subsection{Organize communication and discussion}

Electronic technology experiment is often organized as a team. After students complete inquiry learning, teachers should organize students to discuss the prombles and questions they found, also the inspiration and experience they learmed. In the process of the discussion, students inspire each other and summarize the regulatities of inquiry experiment. They share the collective wisdom and thus strengthen the learning effect and exercise the ability of thinking and expression.

\subsection{Write experiment report}

"No summary, no improvement." The goal of inquiry teaching is to guide students to master the methods of scientific research preliminarily ${ }^{[5]}$. Therefore, teachers should ask students to record the process and summarize their gains of the experiment. Writing experiment report is a common and effective method to summarize. Experiment report is not a simple laundry list to record the process and results of the experiment. The key point of the report should be the train of thought and the method to solve the problem. Specifically, the report should contain the problems to be solved, the method and procedure have experirnced, the new finding found, the theoretical knowledge applied and the enhancement of understanding. 
By students summarize themselves and teachers make evaluation for them, inquiry experiment realize a process that guiding practice from theory and discovering new knowledge from practice. Students can reach a new height in learning by summarizing experience and drawing lessons.

\section{Summary}

The inquiry experiment requires teachers good at choosing subjects and enlightening students with scientific research methods. Teachers should make efforts to explore and innovate constantly tofind a practical and effective way to make experimental teaching play a better role in improving students' quality.

\section{References}

[1] Gu Mingyuan, The dictionary of education, Shanghai education press, 1998.

[2] Li Sen, Yu Zeyuan, Understanding of several theoretical problems in inquiry teaching, Education research, vol 2, 83-85, 2015.

[3] Zhou Yiwu, A guide to amplifying circuits, Fujian science and technology press. 2014.

[4] Luo Gouqiang, Luo We. Practical analog electronic technology project tutorial, Science press, 2009.

[5] Yiqing. On the Application of Inquiry Teaching in the Classroom of Electronic Technology [J]. Reading and Writing (Educational and Teaching Journal), 2010, 7 (09): 184. 